\title{
MicroRNA Functions in Thymic Biology: Thymic Development and Involution
}

\author{
Minwen $\mathrm{Xu}^{1}$, Tao Gan ${ }^{2}$, Huiting Ning ${ }^{2}$ and Liefeng Wang ${ }^{2 *}$ \\ ${ }^{1}$ First Affiliated Hospital of Gannan Medical University, Ganzhou, China, ${ }^{2}$ Department of Biotechnology, Gannan Medical \\ University, Ganzhou, China
}

During the entire processes of thymus organogenesis, maturation, and involution, gene regulation occurs post-transcriptionally via recently discovered microRNA (miRNA) transcripts. Numerous reports indicate that miRNAs may be involved in the construction of a normal thymic microenvironment, which constitutes a critical component to support T lymphocyte development. MiRNAs are also expressed in thymic stromal cells including thymic epithelial cells (TECs) during maturation and senescence. This review focuses on the function of miRNAs in thymic development and involution. A better understanding of these processes will provide new insights into the regulatory network of TECs and further comprehension of how genes control TECs to maintain the thymic microenvironment during thymus development and aging, thus supporting a normal cellular immune system.

Susan Mariola Schlenner,

KU Leuven, Belgium

Graham Anderson

University of Birmingham,

United Kingdom

Xiaobin Liu,

University of North Texas Health Science Center, United States

*Correspondence:

Liefeng Wang

469730795@qq.com

Specialty section:

This article was submitted to

Immunological Tolerance and

Regulation,

a section of the journal

Frontiers in Immunology

Received: 08 August 2017

Accepted: 21 August 2018

Published: 11 September 2018

Citation:

Xu M, Gan T, Ning H and Wang L (2018) MicroRNA Functions in Thymic

Biology: Thymic Development and

Involution. Front. Immunol. 9:2063.

doi: 10.3389/fimmu.2018.02063

Keywords: microRNA, thymic epithelial cells, thymic development, thymic involution, thymic microenvironment, thymus aging, regulatory network

\section{INTRODUCTION}

The thymus plays a critical role in the cellular immune system by generating T lymphocytes, which are involved in anti-tumor immunity, anti-viral, and anti-intracellular infections, as well as the establishment of self-tolerance to avoid autoimmune disorders. During the entire process of thymus organogenesis, maturation, and involution, gene regulation not only occurs at the transcriptional level via transcription factors, but is also effected at the post-transcriptional level by microRNA (miRNA) transcripts. The ubiquitous and abundant existence of such small, non-protein-coding miRNAs in worms, plants, and animals plays an important role in the regulation of gene expression primarily at the post-transcriptional level by cleavage and/or translational repression of messenger RNAs. It has become evident that miRNAs control a wide range of developmental and physiological pathways including cell proliferation, differentiation, and apoptosis. Additionally, the deregulation of miRNAs can cause developmental blockage, dysregulation, or disease. Although many phenomena during thymic development and aging are unable to be simply explained by known protein-coding genes, many novel miRNAs have been identified within recent years that are expressed in the thymus. As the systemic miRNA gene profile and their functional characterization during thymic development and aging are gradually elucidated, we have adequate reason to infer that miRNAs may be involved in the construction of the normal thymic microenvironment that supports $\mathrm{T}$ lymphocyte development. In this review, we focus on the specific miRNAs that are involved in the thymic stroma, and how these play a role in thymic epithelial cell (TEC) development. Through understanding these roles, we can obtain new insights regarding the 
regulatory network in TEC maturation and senescence, and further understand how genes control TECs to maintain the thymic microenvironment during thymus development and aging. Our review aims to reveal potential genetic targets and identify possible therapeutic tools for patients with thymic developmental diseases, which may lead to novel strategies to rejuvenate the functions of an aged thymus or delay thymic aging.

\section{MIRNA IDENTIFICATION AND CHARACTERIZATION}

MiRNAs comprise a large group of conserved, single-stranded, non-coding, abundant, short ( $21-25$ nucleotide) RNAs $(1,2)$. They differ from small interfering RNAs (siRNAs) as they have molecular origins that derive from genomic loci whereas siRNAs are generated from exogenous RNA, such as viral infection, artificial RNA interference (RNAi), and endogenous transposon activity. A miRNA binds to a target mRNA through imperfect complementarity, generally at multiple sites, whereas a siRNA binds to a target mRNA to form an almost perfect duplex at only one site. However, the maturation of both miRNAs and siRNAs utilizes the common RNase-III processing enzyme, Dicer (3), prior to becoming single-stranded anti-sense RNA.

The first microRNA, lin-4 RNA, was identified in 1993 (4). It encodes a 22-nucleotide non-coding RNA that is imperfectly or partially complementary to seven conserved sites located in the $3^{\prime}$-untranslated regions of lin-14, a nuclear protein gene in Caenorhabditis elegans. Although this small RNA was overlooked for seven years as these short non-coding RNAs were considered to be non-existent beyond nematodes, this was completely changed by the discovery of the let-7 gene in 2000 . Notably, let-7 was present not only in C. elegans but also in human and fly genomes. Currently, miRNAs are accepted as phylogenetically conserved genes and have been found in all metazoan genomes, with close to 1,000 miRNAs having been identified in C. elegans, C. briggsae, Drosophila melanogaster, Arabidopsis thaliana, rice, mouse, rat, and human to date (5-7).

MiRNAs are considered to represent novel biological regulators, as they regulate gene expression in a sequence-specific manner. Their primary role is to function as a negative genetic switch, which is involved in post-transcriptional regulation by targeting mRNAs for cleavage, translational repression, or chromatin modification $(1,8,9)$. Recently, additional miRNA functions have been discovered including the control of developmental stages (10-12), hematopoietic cell lineage decisions (13-15), cellular proliferation, cell death/apoptosis (16-19), fat metabolism (20-22), neuronal patterning in nematodes (23-25), asymmetric expression in chemosensory neurons, and involvement in oncogenesis (26-29).

To effect such functions, the expression of miRNA is temporal and spatial in specific tissues. This implies the existence of different miRNAs that are expressed in the various thymus

Abbreviations: Aire, autoimmune regulator; cTEC, cortical thymic epithelial cell; DP, double positive; iNKT, invariant natural killer T cell; IR, ionizing radiation; miRNA, microRNA; mTEC, medullary thymic epithelial cell; TEC, thymic epithelial cell. compartments, cell types, and developmental stages, and that expression patterns may differ between fetal and adult thymi.

\section{MIRNAS IN THYMOCYTE DEVELOPMENT}

The thymus constitutes one of the most active organs in animal life. It undergoes organogenesis (cell migration, proliferation, and differentiation), development (proliferation, differentiation, and cell apoptosis), and involution (cell senescence and apoptosis). The thymus also generates $\mathrm{T}$ lymphocytes to support the cellular immune system. Generally, there are two main processes that interact and regulate each other during thymus development: T lymphocyte development to generate functional $\mathrm{T}$ cells, and stromal cell development to build up and maintain the thymic microenvironment for supporting $\mathrm{T}$ cell maturation, largely through TECs. Both of these processes represent stepwise or sequential pathways in development $(30,31)$.

Thymic involution results in marked morphological and functional changes; these mechanisms include TEC-driven programmed thymic involution and thymocyte apoptosis. Thymic involution results from multiple causes, which can easily be grouped into those arising from normal physiology including pregnancy and aging, and those from various pathophysiological mechanisms, such as infection, malnutrition, disease, and surgery. In particular, thymic aging involution comprises a physically progressive process that can be sped up by infections, autoimmune diseases, or cancer. In addition, a large category of pathophysiological changes can also lead to thymic involution, with infection representing a notable example (32-35).

Because miRNAs are involved in many important development events, it is not difficult to infer that numerous miRNAs are likely involved in regulating the many activities of TECs and thymocytes. Moreover, recent studies have shown that some miRNAs are present in the total thymus and are involved in $\mathrm{T}$ or B lymphocyte lineage determination (36-38), as well thymocyte survival. Moreover, deletion of the Dicer processing enzyme has an effect on thymocyte survival (39). Dicer promotes the development of regulatory $\mathrm{CD}^{+} \mathrm{T}$ ( $\mathrm{T}$ reg) cells in the thymus and the efficient induction of Foxp 3 by TGF- $\beta$, whereas deletion of Dicer decreases $\mathrm{T}$ reg cell numbers and results in immune pathology (40). Natural T reg cells share partial overlap of miRNA expression with conventional $\mathrm{CD} 4^{+} \mathrm{T}$ cells. In turn, conventional $\mathrm{CD}^{+} \mathrm{T}$ cells can express CD25, CTLA4, and GITR, markers, which are also constitutively expressed by $\mathrm{T}$ reg cells during activation (41). Dicer deletion can also result in a distinct reduction of invariant natural killer $\mathrm{T}$ (iNKT) cells in the thymus and other organs with immune functions, which indicates that the Dicer-dependent miRNA pathway plays a critical role in iNKT cell development, function, and homeostasis (42-44).

Two prominent examples of miRNAs expressed in the thymus are miR-181 and miR-150. MiR-181 is highly expressed in double positive (DP) thymocytes and controls the development of early thymocyte cells by targeting CD69 and TCR $(45,46)$. MiR-181a, a member of the miR-181 family, controls the development of early thymocyte cells by regulating and controlling the negative 
feedback loops that establish the NOTCH1 and TCR signaling pathway thresholds $(47,48)$. In particular, these thresholds play important roles in thymic T-cell positive and negative selection, with deletion of miR-181a leading to a decrease of the early thymic progenitor cells, DN3, DP, and single positive (SP) (47). MiR-181a deletion also impairs the development of invariant $\alpha \beta$ NK-T cells, which are agonist-selected at the DP stage $(49,50)$; however, miR-181a-1/b-1 is not critically required for the innate development of $\gamma \delta$ NKT cells or any other $\gamma \delta$ T cell subtypes $(51,52)$.

In comparison, miR-150 can target $c-M y b$ and plays an important role in lymphocyte development and physiology (53). In human $\mathrm{T}$ lymphocytes, miR-150 is obviously up-regulated during $\mathrm{T}$ cell maturation after the DP stage and targets Notch3, which plays an important role in T cell development (54). Overexpression of miR-150 can reduce the number of $\mathrm{T}$ cell lines in vitro by impacting their proliferation and survival. MiR-150 is also expressed in iNKT cells and targets $c-M y b$ (55). MiR150 over-expression increases iNKT maturation whereas deletion of the miRNA results in an interruption of iNKT cell final maturation in both the thymus and the peripheral space (56).

In addition, some other miRNAs, such as miR-155 (57-59), miR-19b (60), let-7 (61), and miR-17 (62), have been reported to play important roles in lymphocyte maturation, differentiation, development, and survival. The roles of certain miRNA candidates in thymocyte biology are listed in Table $\mathbf{1 .}$

\section{MIRNAS IN TEC BIOLOGY}

As described above, TECs have three maturation stages, which can be segregated according to cell surface molecules (63). In wild type thymus, TECs completely differentiate into the three-dimensional cortical and medullar network TEC system.

TABLE 1 | The role of candidate miRNAs in thymocyte biology.

\begin{tabular}{|c|c|c|c|c|}
\hline miRNAs & Cell type & Biologic role & Targets & References \\
\hline \multirow[t]{2}{*}{ miR-150 } & T cell & Maturation of $\mathrm{T}$ cells & NOTCH3 & (54) \\
\hline & NKT/iNKT & $\begin{array}{l}\text { Development of NKT } \uparrow \\
\text { iNKT } \downarrow\end{array}$ & C-Myc & $(55,56)$ \\
\hline \multirow[t]{2}{*}{ miR-155 } & iNKT & $\begin{array}{l}\text { Maturation and } \\
\text { differentiation of iNKT } \downarrow\end{array}$ & Ets1, ITK & $(57)$ \\
\hline & Treg & Development of Tregs $\uparrow$ & Foxp3 & $(58,59)$ \\
\hline \multirow[t]{2}{*}{$\begin{array}{l}\text { miR-181a- } \\
1 / b-1\end{array}$} & $\begin{array}{l}\text { T cell } \\
\text { Leukemia } \\
\text { cell }\end{array}$ & Development & NOTCH1 & $(47)$ \\
\hline & iNKT & Development of iNKT $\uparrow$ & $\begin{array}{l}\text { Ptpn22, } \\
\text { Shp-2, Dusp6 }\end{array}$ & (49) \\
\hline miR-181 & NKT & Maturation of NKT & PTEN & \\
\hline miR-181a & $\mathrm{T}$ cell & $\begin{array}{l}\text { T cell sensitivity and } \\
\text { selection }\end{array}$ & & $(48)$ \\
\hline miR-181d & $\mathrm{CD}^{+}{ }^{+} \mathrm{CD} 8+$ & ${ }^{+}$Immature $\mathrm{CD}^{+}{ }^{+} \mathrm{CD}^{+} \downarrow$ & Foxo4, Myc & $(52)$ \\
\hline miR-19b & Th17 & Development of Th17 & Tslp & $(60)$ \\
\hline let-7 & NKT & & Zbtb16 & $(61)$ \\
\hline $\mathrm{miR}-17$ & T cell & Survival & Jak1 & $(62)$ \\
\hline
\end{tabular}

However, in the various stages of lymphocyte development identified by mutating the thymus, TECs themselves are arrested at different stages, indicating that TEC differentiation is tightly dependent on T-cell development. For example, in the thymus of mice with an Ikaros-null mutation (64) or the RAG2/common chain compound gene knock-out mutant thymus (64-66), which display distinct defects in the development of fetal and adult lymphocytes, the TECs are arrested during the early twodimensional cortical TEC stage (67), whereas in the RAG null thymus, TECs are arrested in the middle three-dimensional stage.

As the expression of miRNAs is tightly regulated during tissue differentiation (68) and miRNAs can function to prevent cell division and drive terminal differentiation (69), miRNAs are therefore likely to be involved in thymic differentiation. Consistent with this supposition, a role of miRNAs in TEC biology has been demonstrated. In particular, miRNA microarray analysis of cortical thymic epithelial cells (cTECs) along with immature medullary thymic epithelial cell (mTEC) $)^{\text {low }}$ and mature mTEC $^{\text {high }}$ cells indicated that miRNA expression differs among thymic cell subsets and fluctuates during TEC maturation (70). When Dicer was conditionally deleted in all TECs, thymus cellularity was decreased and the thymus failed to maintain a regular microenvironment (71). Moreover, mTEC apoptosis was enhanced in these mice, in which cTEC failed to impose efficient positive selection, $\mathrm{T}$ cell phenotypes were changed, and $\mathrm{T}$ lymphopoietic activity was decreased $(71,72)$. To further clarify the function of canonical miRNAs in TECs, DGCR8, encoding a component of the miRNA-specific microprocessor complex, was deleted (73). DGCR8 is critical for maintaining the proper expression of Aire, the gene for which is specifically expressed in the TEC compartment and affects TEC function, along with the overall architecture of the thymic medulla. Furthermore, miRNA deficiency in TECs causes a breakdown in central tolerance (73).

\section{MIRNAS IN THYMIC INVOLUTION}

Although the mechanism of thymic involution remains unclear, certain miRNAs have been reported to be involved in thymic aging involution. Microarray data analysis shows that some microRNAs are significantly changed in aged thymuses, with quantitative polymerase chain reaction (qPCR) data confirming these changes (74). In particular, miR-181a-5p has been hypothesized to be associated with thymic aging involution as its expression is obviously decreased in TECs from aged mice. To test this hypothesis, a miR-181a-5p mimic was used in a mouse mTEC cell line (MTEC1). The miR-181a-5p mimic could induce cell proliferation of MTEC1 whereas its inhibitor reversed this effect. MiR-181a-5p was shown to target transforming growth factor beta receptor $(T g f b r 1)$ gene using a luciferase reporter assay (75). Furthermore, the miR-181a-5p mimic could decrease Tgfbr1 protein expression as well as that of $\mathrm{p}-\mathrm{Smad} 3$, is a key node of the TGF- $\beta$ signaling pathway, in vitro. Tgfbr1 expression increases with age in mice, which is consistent with the decreased level of miR-181a-5p in addition to the ability of TGF- $\beta$ to decrease the proliferation of mTECs. 
In comparison, FoxN1 constitutes a pivotal transcription factor for TEC survival and differentiation, which decreases with age. WNT signaling in thymic epithelia is essential for normal thymus development and function (76) but is suppressed in the senescent human thymus (77). WNT4 can directly up-regulate FoxN1, indicating that miRNAs that target FoxN1 or the WNT signaling pathway may be involved in thymic aging involution (78). Consistent with this, a study comparing the difference in miRNA expression between old and young thymi (from 70-yearold men vs. $<10$-month-old newborns, respectively) found that some miRNAs that act as modulators of the WNT pathway, such as miR-25, miR-7f, and miR-134, were among those altered (79).

Moreover, in a previous study from our laboratory, we compared changes in miRNA expression profiles between young and aged TECs using miRBase-V20 arrays (containing 1,892 unique probes), which clearly identified and validated that at least one miRNA, miR-125a-5p, was increased in aged thymi (80). In addition, the application of a miR-125a-5p mimic was able to inhibit FoxN1 expression (as indicated using $3^{\prime}$ UTR luciferase activity) in a 293T cell line and suppress FoxN1 expression in TEC Z210 cells (80).

The thymus represents an organ that is hyper-responsive to stress in the form of infections, radiation exposure, trauma, and drugs. Infection can induce a rapid yet transient atrophy, which is distinct from thymic aging involution. Such atrophy can recur after exposure to pathogen-associated molecular patterns (PAMPs) (81).

There is mounting evidence that miRNA expression is associated with stress. Some miRNAs might serve as potential biomarkers of stress specifically in the thymus: for example, the expression of miR-21 is increased during radiation-induced thymic lymphoma and its expression could be induced by the TGF- $\beta$ (82) and by the TLR4 pathway (83). MiR-23a/b is also up-regulated in radiation-induced thymic lymphoma (84). MiRNAs may also play significant roles in protective mechanisms for counteracting stress. In particular, miR-34a and miR-7 may counteract radiation cytotoxicity by respectively targeting NOTCH1, MYC, E2F3, cyclin D1, and lymphoid-specific helicase (LSH) (85).

Alternatively, some miRNAs may play a reverse role. For example, miR-467a directly targets Fas and/or Bax and may have oncogenic functions in radiation-induced thymic lymphoma (86). Together, the evidence suggests that some miRNAs might serve as new biomarkers of stress-induced thymic injury or as novel therapeutic targets of stress-induced thymic injury. Moreover, some miRNAs might be suitable for use as drugs to treat stress-induced thymic injury. The potential roles of candidate miRNAs in thymic biology are listed in Table 2.

\section{MIRNAS DIRECTLY TARGET SIGNAL PATHWAY GENES OR VICE VERSA}

The adult thymic microenvironment consists of epithelial cells, fibroblastoid cells, dendritic cells, and macrophages. Epithelial cells represent the resident cell type of the thymic microenvironment. Their development and differentiation
TABLE 2 | The role of candidate miRNAs in thymic biology.

\begin{tabular}{llll}
\hline miRNAs & $\begin{array}{l}\text { Organism } \\
\text { status/biologic role }\end{array}$ & Targets & References \\
\hline $\begin{array}{l}\text { miR-181a-5p } \\
\text { miR-125a-5p }\end{array}$ & $\begin{array}{l}\text { Aging involution } \\
\text { Aging involution }\end{array}$ & smad3 & $(75)$ \\
miR-25 & Aging involution & FoxN1 & $(80)$ \\
miR-7f & & WNT & $(79)$ \\
miR-134 & & & \\
miR-29a & Infection & Ifnar1 & \\
miR-205 & Inflammatory & FoxN1 & \\
miR-182 & Toxicity & AhR, CYP1A1, & \\
miR-31 & & Fas, FasL & \\
miR-23a & & & \\
miR-18b & & & \\
mmu-let-7e & & & \\
miR-34a & IR-inducible involution & NOTCH1, MYC, & $(85)$ \\
& & E2F3, Cyclin D1 & \\
miR-7 & & LSH & \\
miR-21 & IR-inducible involution & Big-h3 & $(82,83)$ \\
miR-27b & IR-inducible involution & Cyclin A2 & \\
miR-23a/b & IR-inducible thymic lymphoma & Fas & $(84)$ \\
miR-23a/b & IR-inducible thymic lymphoma & Fas/Bax \\
\hline
\end{tabular}

depend on a variety of signaling pathways, such as WNT (87), tumor necrosis factor receptor (TNFR) and the downstream NF-кB (88), BMP (89), IFNAR1 pathway (72), and TGF-beta (90) signaling. Interferon (IFN)- $\alpha$, a critical molecular mediator of pathogen-induced thymic involution, mediates rapid and transient involution by binding IFNAR1, which is expressed on the thymic stroma (81). The Dicer-dependent miRNA network, and specifically miR-29a, is critical for reducing the sensitivity of the thymic epithelium to simulated infection signals, protecting the thymus against infection-associated thymic involution. Loss of Dicer or the miR-29a cluster in the thymic epithelium results in IFNAR1-dependent hypersensitivity to pathogen-related signals, thereby allowing suboptimal signals to trigger the rapid loss of thymic cellularity (91).

TGF- $\beta$ signaling might also play an important role in controlling thymus development and maintenance (92), especially by increasing the size of the mTEC compartment and enhancing negative selection and functional maturation of medullary thymocytes (93). The TGF- $\beta$ pathway components, such as receptors or transcription factors, might thus serve as targets of miRNAs. Consistent with this, TGF- $\beta$ receptor 1 was confirmed as a direct target of miR-181a-5p by luciferase assay (75). Over expression of miR-181a-5p down-regulated the phosphorylation of Smad3 and blocked the activation of TGF- $\beta$ signaling. In turn, Smad7, which functions as a regulator of the TGF- $\beta$ signaling pathway by preventing the phosphorylation of Smad2/3, was confirmed as a direct target of miR-195a-5p. Notably, miR-195a-5p is up-regulated in mouse TECs and over-expression of miR-195a-5p inhibits the expression of TEC cell cycle-related genes including those encoding cyclin D1, 
cyclin E1, Cdk4, and C-myc by down-regulating the expression of Smad7 (94).

The TNFR and NF-кB pathway constitutes another important pathway for mTEC development, which is required to successfully establish the medullary microenvironment (88). Specifically, mice deficient for receptor activator of NF- $\mathrm{B}$ (RANK) exhibit variable defects in mTECs (95). MiRNAs also participate in this signaling pathway and regulate mTEC differentiation. For example, RANK ligand and downstream canonical or non-canonical NF- $\kappa \mathrm{B}$ can induce the expression of miR-449a. In turn, overexpression of miR-449a as well as miR-34a, which shares similar seed sequence with miR-449a, may induce TEC differentiation in vitro by targeting SATB2 (an epigenetic regulator identified as an miRN-449a target in colorectal tumor cells (96), as SATB2 was significantly decreased in a thymic epithelial progenitor cell line following miR-449a overexpression (91).

\section{MIRNAS DIRECTLY TARGET TRANSCRIPTION FACTOR GENES OF THYMIC STROMAL CELL HOMEOSTASIS}

Transcription factors Foxn1 and p63 also play crucial roles in thymic biology. Foxn 1 has an important function in TEC survival and differentiation by promoting thymic epithelial progenitor cells to differentiate into functional mTECs and cTECs during organogenesis $(97,98)$ and for postnatal TEC homeostasis (99, 100). p63 is important for the development of the thymus (101) and is essential for the proliferative potential of thymic epithelial progenitor cells $(101,102)$. Several reports have shown that miRNAs participate in TEC development and differentiation by directly targeting the Foxn1 gene. For example, Kushwaha et al., screened out two miRNAs, miR-18b and miR-518b, that directly targeted Foxn1 (103). Their results demonstrate that miR-18b and miR-518b act as upstream controllers of Foxn1 in epithelial cell development. Moreover, interfering with these miRNAs individually or together can up-regulate Foxn1 gene expression whereas their individual or combined over-expression can decrease Foxn 1 protein levels. In turn, miR-22 also regulates epithelial cell development via direct inhibition of Foxn1 (104).

p63 also serves as a target of numerous miRNAs. 29MiR203 has immediate and long-term impact on epidermal cell proliferation by directly regulating p63 (105-107). The regulation of 663 by IASPP, an inhibitory member of the apoptosis stimulating protein of p53 (ASPP) family, via miR-574-3p and miR-720 is required for epithelial homeostasis (108). Notably, p63-mediated cell cycle progression in epidermal cells occurs through the direct repression of miR-34a and miR-34c (109).

\section{REFERENCES}

1. Bartel DP. MicroRNAs: genomics, biogenesis, mechanism, and function. Cell (2004) 116:281-97. doi: 10.1016/S0092-8674(04)00045-5

2. Lee Y, Kim M, Han J, Yeom KH, Lee S, Baek SH, et al. MicroRNA genes are transcribed by RNA polymerase II. EMBO J. (2004) 23:4051-60. doi: 10.1038/sj.emboj.7600385
Furthermore, several miRNAs, such as miR-192/215, miR-107, miR-96,132, and miR-145, are known transcriptional targets of p63. In particular, the role of the p63-FoxN1 regulatory axis in the regulation of postnatal TEC homeostasis has been revealed by Burnley et al. (110), Overall, miRNA function can be defined as having a fine-tuning effect by targeting the $\mathrm{p} 63$-FoxN1 regulatory axis.

Aire constitutes another transcription factor that controls peripheral tissue-restricted antigens in mTECs. miR-29a deletion resulted in a progressive decrease in expression of Aire and Airedependent genes in miR-29a null mutant mice (70). In addition, miR-220b may act as a possible regulatory factor for Aire gene translation as it could significantly reduce the expression of Aire protein (111).

\section{PERSPECTIVES}

MiRNAs play important roles in the processes of thymus organogenesis, maturation, and involution at a posttranscriptional level by targeting relevant mRNAs. Herein, we reviewed some of the miRNAs involved in thymocyte development, thymic architecture, thymic aging involution, and thymic involution during stress. We hope this review will help to deepen the appreciation of miRNA impact on thymic biology and facilitate the identification of potential candidates for therapeutic targeting. In addition, we checked miRNA profiles of serum-derived exosomes from young and aged mice with microarray of Mus musculus miRBase version-21 array chips and we found that young and old showed different miRNA expression profiles (112). These different spectrums of microRNAs in the young and old exosomes may generate a base for a potential epigenetic regulation and may play important roles in the processes of thymus organogenesis, maturation, and involution.

\section{AUTHOR CONTRIBUTIONS}

MX and LW wrote the paper. TG and HN reviewed and edited the manuscript. All authors read and approved the manuscript.

\section{FUNDING}

This work was supported in part by the Science and Technology Project Foundation of Education Department of Jiangxi Provincial (GJJ150961) to MX, the Natural Science Foundation of Jiangxi Province (20132BAB205032), and the National Natural Science Foundation of China (31260279 and 31660256) to LW.
3. Ketting RF, Fischer SE, Bernstein E, Sijen T, Hannon GJ, Plasterk RH. Dicer functions in RNA interference and in synthesis of small RNA involved in developmental timing in C. elegans. Genes Dev. (2001) 15:2654-9. doi: 10.1101/gad.927801

4. Lee RC, Feinbaum RL, Ambros V. The C. elegans heterochronic gene lin-4 encodes small RNAs with antisense complementarity to lin-14. Cell (1993) 75:843-54. 
5. Griffiths-Jones S. The microRNA Registry. Nucleic Acids Res. (2004) 32:D109-11. doi: 10.1093/nar/gkh023

6. He L, Hannon GJ. MicroRNAs: small RNAs with a big role in gene regulation. Nat Rev Genet. (2004) 5:522-31. doi: 10.1038/nrg1379

7. Bentwich I, Avniel A, Karov Y, Aharonov R, Gilad S, Barad O, et al. Identification of hundreds of conserved and nonconserved human microRNAs. Nat Genet. (2005) 37:766-70. doi: 10.1038/nrg1590

8. Pepin G, Gantier MP. MicroRNA decay: Refining microRNA regulatory activity. Microrna (2016) 5:167-74. doi: $10.2174 / 2211536605666161027165915$

9. Ambros, V. The functions of animal microRNAs. Nature (2004) 431:350-5. doi: 10.1038/nature02871

10. Leong JW, Sullivan RP, Fehniger TA. MicroRNA management of NK-cell developmental and functional programs. Eur J Immunol. (2014) 44:2862-8. doi: 10.1002/eji.201444798

11. Zhang H, Artiles KL, Fire AZ. Functional relevance of "seed" and "non-seed" sequences in microRNA-mediated promotion of C. elegans developmental progression. RNA (2015) 21:1980-92. doi: 10.1261/rna.053793.115

12. Constantin L, Constantin M, Wainwright BJ. MicroRNA biogenesis and Hedgehog-Patched signaling cooperate to regulate an important developmental transition in granule cell development. Genetics (2016) 202:1105-18. doi: 10.1534/genetics.115.184176

13. Chen S, Wang Z, Dai X, Pan J, Ge J, Han X, et al. Re-expression of microRNA150 induces EBV-positive Burkitt lymphoma differentiation by modulating c-Myb in vitro. Cancer Sci. (2013) 104:826-34. doi: 10.1111/cas.12156

14. Chen MT, Lin HS, Shen C, Ma YN, Wang F, Zhao HL, et al. PU.1-regulated long noncoding RNA lnc-MC controls human monocyte/macrophage differentiation through interaction with microRNA 199a-5p. Mol Cell Biol. (2015) 35:3212-24. doi: 10.1128/MCB.00429-15

15. Georgantas RW III, Hildreth R, Morisot S, Alder J, Liu CG, Heimfeld S, et al. CD34+ hematopoietic stem-progenitor cell microRNA expression and function: a circuit diagram of differentiation control. Proc Natl Acad Sci USA. (2007) 104:2750-5. doi: 10.1073/pnas.0610983104

16. Mobarra N, Shafiee A, Rad SM, Tasharrofi N, Soufi-Zomorod M, Hafizi M, et al. Overexpression of microRNA-16 declines cellular growth, proliferation and induces apoptosis in human breast cancer cells. In Vitro Cell Dev Biol Anim. (2015) 51:604-11. doi: 10.1007/s11626-015-9872-4

17. Li Y, Chen D, Jin L, Liu J, Su Z, Gui Y, et al. MicroRNA-20b-5p functions as a tumor suppressor in renal cell carcinoma by regulating cellular proliferation, migration and apoptosis. Mol Med Rep. (2016) 13:1895-901. doi: $10.3892 / \mathrm{mmr} .2015 .4692$

18. Li Y, Chen D, Jin LU, Liu J, Su Z, Qi Z, et al. Oncogenic microRNA-142-3p is associated with cellular migration, proliferation and apoptosis in renal cell carcinoma. Oncol Lett. (2016) 11:1235-41. doi: 10.3892/ol.2015.4021

19. Lenkala D, LaCroix B, Gamazon ER, Geeleher P, Im HK, Huang RS. The impact of microRNA expression on cellular proliferation. Hum Genet. (2014) 133:931-8. doi: 10.1007/s00439-014-1434-4

20. Xu P, Vernooy SY, Guo M, Hay BA. The Drosophila microRNA Mir-14 suppresses cell death and is required for normal fat metabolism. Curr Biol. (2003) 13:790-5. doi: 10.1016/S0960-9822(03)00250-1

21. Meerson A, Traurig M, Ossowski V, Fleming JM, Mullins M, Baier LJ. Human adipose microRNA-221 is upregulated in obesity and affects fat metabolism downstream of leptin and TNF-alpha. Diabetologia (2013) 56:1971-9. doi: 10.1007/s00125-013-2950-9

22. Benatti RO, Melo AM, Borges FO, Ignacio-Souza LM, Simino LA, Milanski $\mathrm{M}$, et al. Maternal high-fat diet consumption modulates hepatic lipid metabolism and microRNA-122 (miR-122) and microRNA370 (miR-370) expression in offspring. Br J Nutr. (2014) 111:2112-22. doi: $10.1017 /$ S0007114514000579

23. Johnston RJ, Hobert O. A microRNA controlling left/right neuronal asymmetry in Caenorhabditis elegans. Nature (2003) 426:845-9. doi: 10.1038/nature02255

24. Hsieh YW, Chang C, Chuang CF. The microRNA mir-71 inhibits calcium signaling by targeting the TIR-1/Sarm1 adaptor protein to control stochastic L/R neuronal asymmetry in C. elegans. PLoS Genet. (2012) 8: e1002864. doi: 10.1371/journal.pgen.1002864

25. Chang S, Johnston RJ Jr, Frøkjaer-Jensen C, Lockery S, Hobert O. MicroRNAs act sequentially and asymmetrically to control chemosensory laterality in the nematode. Nature (2004) 430:785-9. doi: 10.1038/nature02752

26. Sun L, Wang Q, Gao X, Shi D, Mi S, Han Q. MicroRNA-454 functions as an oncogene by regulating PTEN in uveal melanoma. FEBS Lett. (2015) 589:2791-6. doi: 10.1016/j.febslet.2015.08.007

27. Krause CJ, Popp O, Thirunarayanan N, Dittmar G, Lipp M, Müller G. MicroRNA-34a promotes genomic instability by a broad suppression of genome maintenance mechanisms downstream of the oncogene KSHVvGPCR. Oncotarget (2016) 7:10414-32. doi: 10.18632/oncotarget.7248

28. Bueno MJ, Pérez de Castro I, Gómez de Cedrón M, Santos J, Calin GA, Cigudosa JC, et al. Genetic and epigenetic silencing of microRNA-203 enhances ABL1 and BCR-ABL1 oncogene expression. Cancer Cell (2016) 29:607-8. doi: 10.1016/ccr.2008.04.018

29. Fukumoto I, Koshizuka K, Hanazawa T, Kikkawa N, Matsushita R, Kurozumi A, et al. The tumor-suppressive microRNA-23b/27b cluster regulates the MET oncogene in oral squamous cell carcinoma. Int J Oncol. (2016) 49:111929. doi: 10.3892/ijo.2016.3602

30. Klug DB, Carter C, Crouch E, Roop D, Conti CJ, Richie ER. Interdependence of cortical thymic epithelial cell differentiation and T-lineage commitment. Proc Natl Acad Sci USA. (1998) 95:11822-7.

31. van Ewijk W, Holländer G, Terhorst C, Wang B. Stepwise development of thymic microenvironments in vivo is regulated by thymocyte subsets. Development (2000) 127:1583-91.

32. Szeri I, Anderlik P, Bános Z, Wessely M. Bacterial modulation of the cellular immune response in mice. I. The course of lymphocytic choriomeningitis virus infection in Bordetella pertussis vaccine pretreated mice with physiological thymus involution. Acta Microbiol Hung. (1983) 30:227-32.

33. Knobler RL, Oldstone MB. Infection and involution of mouse thymus by MHV-4. Adv Exp Med Biol. (1987) 218:451-3.

34. Szeri I, Anderlik P, Bános Z, Barna Z. [Effect of microbial immunomodulators on the course of lymphocytic choriomeningitis virus infection in old mice with physiological thymus involution]. Acta Pharm Hung. (1991) 61:246-52.

35. Szeri I, Anderlik P, Bános Z, Barna Z. Effect of microbial immunomodulants on the course of LCMV infection in old mice with thymus involution. Acta Microbiol Hung. (1992) 39:13-9.

36. Bartel DP, Chen CZ. Micromanagers of gene expression: the potentially widespread influence of metazoan microRNAs. Nat Rev Genet. (2004) 5:396400. doi: $10.1038 / \mathrm{nrg} 1328$

37. Barad O, Meiri E, Avniel A, Aharonov R, Barzilai A, Bentwich I, et al. MicroRNA expression detected by oligonucleotide microarrays: system establishment and expression profiling in human tissues. Genome Res. (2004) 14:2486-94. doi: 10.1101/gr.2845604

38. Monticelli S, Ansel KM, Lee DU, Rao A. Regulation of gene expression in mast cells: micro-rNA expression and chromatin structural analysis of cytokine genes. Novartis Found Symp. (2005) 271:179-87.

39. Cobb BS, Nesterova TB, Thompson E, Hertweck A, O'Connor E, Godwin J, et al. $\mathrm{T}$ cell lineage choice and differentiation in the absence of the RNase III enzyme Dicer. J Exp Med. (2005) 201:1367-73. doi: 10.1084/jem200 50572

40. Muljo SA, Ansel KM, Kanellopoulou C, Livingston DM, Rao A, Rajewsky K. Aberrant T cell differentiation in the absence of Dicer. J Exp Med. (2005) 202:261-9. doi: 10.1084/jem20050678

41. Cobb BS, Hertweck A, Smith J, O'Connor E, Graf D, Cook T, et al. A role for Dicer in immune regulation. J Exp Med. (2006) 203:2519-27. doi: $10.1084 /$ jem. 20061692

42. Fedeli M, Napolitano A, Wong MP, Marcais A, de Lalla C, Colucci F, et al. Dicer-dependent microRNA pathway controls invariant NKT cell development. J Immunol. (2009) 183:2506-12. doi: 10.4049/jimmunol.0901361

43. Zhou L, Seo KH, He HZ, Pacholczyk R, Meng DM, Li CG, et al. Tie2creinduced inactivation of the miRNA-processing enzyme Dicer disrupts invariant NKT cell development. Proc Natl Acad Sci USA. (2009) 106:1026671. doi: 10.1073/pnas.0811119106

44. Seo KH, Zhou L, Meng D, Xu J, Dong Z, Mi QS. Loss of microRNAs in thymus perturbs invariant NKT cell development and function. Cell Mol Immunol. (2010) 7:447-53. doi: 10.1038/cmi.2010.49 
45. Ebert PJ, Jiang S, Xie J, Li QJ, Davis MM. An endogenous positively selecting peptide enhances mature $\mathrm{T}$ cell responses and becomes an autoantigen in the absence of microRNA miR-181a. Nat Immunol. (2009) 10:1162-9. doi: 10.1038/ni.1797

46. Liu J, Wu CP, Lu BF, Jiang JT. Mechanism of T cell regulation by microRNAs. Cancer Biol Med. (2013) 10:131-7. doi: 10.7497/j.issn.2095-3941.2013.03.002

47. Fragoso R, Mao T, Wang S, Schaffert S, Gong X, Yue S, et al. Modulating the strength and threshold of NOTCH oncogenic signals by mir-181a-1/b-1. PLoS Genet. (2012) 8:e1002855. doi: 10.1371/journal.pgen.1002855

48. Li QJ, Chau J, Ebert PJ, Sylvester G, Min H, Liu G, et al. miR-181a is an intrinsic modulator of T cell sensitivity and selection. Cell (2007) 129:147-61. doi: 10.1016/j.cell.2007.03.008

49. Henao-Mejia J, Williams A, Goff LA, Staron M, Licona-Limón P, Kaech SM, et al. The microRNA miR-181 is a critical cellular metabolic rheostat essential for NKT cell ontogenesis and lymphocyte development and homeostasis. Immunity (2013) 38:984-97. doi: 10.1016/j.immuni.2013.02.021

50. Zietara N, Lyszkiewicz M, Witzlau K, Naumann R, Hurwitz R, Langemeier J, et al. Critical role for miR-181a/b-1 in agonist selection of invariant natural killer T cells. Proc Natl Acad Sci USA. (2013) 110:7407-12. doi: 10.1073/pnas.1221984110

51. Sandrock I, Zietara N, Łyszkiewicz M, Oberdörfer L, Witzlau K, Krueger A, et al. MicroRNA-181a/b-1 is not required for innate $\gamma \delta$ NKT effector cell development. PLoS ONE (2015) 10:e0145010. doi: 10.1371/journal.pone. 0145010

52. Belkaya S, van Oers NS. Transgenic expression of microRNA-181d augments the stress-sensitivity of CD4(+)CD8(+) thymocytes. PLoS ONE (2014) 9:e85274. doi: 10.1371/journal.pone.0085274

53. Zhou B, Wang S, Mayr C, Bartel DP, Lodish HF. miR-150, a microRNA expressed in mature B and $\mathrm{T}$ cells, blocks early B cell development when expressed prematurely. Proc Natl Acad Sci USA. (2007) 104:7080-5. doi: 10.1073/pnas.0702409104

54. Ghisi M, Corradin A, Basso K, Frasson C, Serafin V, Mukherjee S, et al. Modulation of microRNA expression in human T-cell development: targeting of NOTCH3 by miR-150. Blood (2011) 117:7053-62. doi: 10.1182/blood-2010-12-326629

55. Bezman NA, Chakraborty T, Bender T, Lanier LL. miR-150 regulates the development of NK and iNKT cells. J Exp Med. (2011) 208:2717-31. doi: 10.1084/jem.20111386

56. Zheng Q, Zhou L, Mi QS. MicroRNA miR-150 is involved in Valpha14 invariant NKT cell development and function. J Immunol. (2012) 188:211826. doi: 10.4049/jimmunol.1103342

57. Burocchi A, Pittoni P, Tili E, Rigoni A, Costinean S, Croce CM, et al. Regulated expression of miR-155 is required for iNKT cell development. Front Immunol. (2015) 6:140. doi: 10.3389/jimmu.2015. 00140

58. Kohlhaas S, Garden OA, Scudamore C, Turner M, Okkenhaug K, Vigorito E. Cutting edge: the Foxp3 target miR-155 contributes to the development of regulatory T cells. J Immunol. (2009) 182:2578-82. doi: 10.4049/jimmunol.0803162

59. Stahl HF, Fauti T, Ullrich N, Bopp T, Kubach J, Rust W, et al. miR-155 inhibition sensitizes CD4+ Th cells for TREG mediated suppression. PLoS ONE (2009) 4:e7158. doi: 10.1371/journal.pone.00 07158

60. Wang Z, Chen Y, Xu S, Yang Y, Wei D, Wang W, et al. Aberrant decrease of microRNA19b regulates TSLP expression and contributes to Th17 cells development in myasthenia gravis related thymomas. J Neuroimmunol. (2015) 288:34-9. doi: 10.1016/j.jneuroim.2015.08.013

61. Pobezinsky LA, Etzensperger R, Jeurling S, Alag A, Kadakia T, McCaughtry $\mathrm{TM}$, et al. Let-7 microRNAs target the lineage-specific transcription factor PLZF to regulate terminal NKT cell differentiation and effector function. Nat Immunol. (2015) 16:517-24. doi: 10.1038/ni.3146

62. Katz G, Pobezinsky LA, Jeurling S, Shinzawa M, Van Laethem F, Singer A. T cell receptor stimulation impairs IL-7 receptor signaling by inducing expression of the microRNA miR-17 to target Janus kinase 1. Sci Signal. (2014) 7:ra83. doi: 10.1126/scisignal.2005221

63. Takahama Y, Ohigashi I, Baik S, Anderson G. Generation of diversity in thymic epithelial cells. Nat Rev Immunol. (2017) 17:295-305. doi: $10.1038 /$ nri.2017.12
64. Wang JH, Nichogiannopoulou A, Wu L, Sun L, Sharpe AH, Bigby M, et al. Selective defects in the development of the fetal and adult lymphoid system in mice with an Ikaros null mutation. Immunity (1996) 5:537-49.

65. Leonard WJ, Shores EW, Love PE. Role of the common cytokine receptor gamma chain in cytokine signaling and lymphoid development. Immunol Rev. (1995) 148:97-114.

66. Colucci F, Soudais C, Rosmaraki E, Vanes L, Tybulewicz VL, Di Santo JP. Dissecting NK cell development using a novel alymphoid mouse model: investigating the role of the $\mathrm{c}$-abl proto-oncogene in murine NK cell differentiation. J Immunol. (1999) 162:2761-5.

67. Klug DB, Carter C, Gimenez-Conti IB, Richie ER. Cutting edge: thymocyte-independent and thymocyte-dependent phases of epithelial patterning in the fetal thymus. J Immunol. (2002) 169:2842-5. doi: 10.4049/jimmunol.169.6.2842

68. Lu J, Getz G, Miska EA, Alvarez-Saavedra E, Lamb J, Peck D, et al. MicroRNA expression profiles classify human cancers. Nature (2005) 435:834-8. doi: 10.1038/nature03702

69. Reinhart BJ, Slack FJ, Basson M, Pasquinelli AE, Bettinger JC, Rougvie $\mathrm{AE}$, et al. The 21-nucleotide let-7 RNA regulates developmental timing in Caenorhabditis elegans. Nature (2000) 403:901-6. doi: 10.1038/35002607

70. Ucar O, Tykocinski LO, Dooley J, Liston A, Kyewski B. An evolutionarily conserved mutual interdependence between Aire and microRNAs in promiscuous gene expression. Eur J Immunol. (2013) 43:1769-78. doi: 10.1002/eji.201343343

71. Zuklys S, Mayer CE, Zhanybekova S, Stefanski HE, Nusspaumer G, Gill J, et al. MicroRNAs control the maintenance of thymic epithelia and their competence for $\mathrm{T}$ lineage commitment and thymocyte selection. J Immunol. (2012) 189:3894-904. doi: 10.4049/jimmunol.1200783

72. Papadopoulou AS, Dooley J, Linterman MA, Pierson W, Ucar O, Kyewski $\mathrm{B}$, et al. The thymic epithelial microRNA network elevates the threshold for infection-associated thymic involution via miR-29a mediated suppression of the IFN-alpha receptor. Nat Immunol. (2011) 13:181-7. doi: 10.1038/ni.2193

73. Khan IS, Taniguchi RT, Fasano KJ, Anderson MS, Jeker LT. Canonical microRNAs in thymic epithelial cells promote central tolerance. Eur J Immunol. (2014) 44:1313-9. doi: 10.1002/eji.201344079

74. Guo Z Chi F Song Y Wang C Yu R Wei T, et al. Transcriptome analysis of murine thymic epithelial cells reveals ageassociated changes in microRNA expression. Int J Mol Med. (2013) 32:835-42. doi: 10.3892/ijmm.2013.1471

75. Guo D, Ye Y, Qi J, Zhang L, Xu L, Tan X, et al. MicroRNA-181a$5 p$ enhances cell proliferation in medullary thymic epithelial cells via regulating TGF-beta signaling. Acta Biochim Biophys Sin. (2016) 48:840-9. doi: 10.1093/abbs/gmw068

76. Zuklys S, Gill J, Keller MP, Hauri-Hohl M, Zhanybekova S, Balciunaite $\mathrm{G}$, et al. Stabilized beta-catenin in thymic epithelial cells blocks thymus development and function. I Immunol. (2009) 182:2997-3007. doi: $10.4049 /$ jimmunol.0713723

77. Wang B, Hollander GA, Nichogiannopoulou A, Simpson SJ, Orange JS, Gutierrez-Ramos JC, et al. Natural killer cell development is blocked in the context of aberrant T lymphocyte ontogeny. Int Immunol. (1996) 8:939-49.

78. Talaber G, Kvell K, Varecza Z, Boldizsar F, Parnell SM, Jenkinson EJ, et al. Wnt-4 protects thymic epithelial cells against dexamethasone-induced senescence. Rejuvenation Res. (2011) 14:241-8. doi: 10.1089/rej.2010.1110

79. Ferrando-Martinez S, Ruiz-Mateos E, Dudakov JA, Velardi E Grillari J, Kreil DP, et al. WNT signaling suppression in the senescent human thymus. $J$ Gerontol A Biol Sci Med Sci. (2015) 70:273-81. doi: 10.1093/gerona/glu030

80. Xu M, Sizova O, Wang L, Su DM. A fine-tune role of mir-125a-5p on Foxn1 during age-associated changes in the thymus. Aging Dis. (2017) 8:277-86. doi: 10.14336/AD.2016.1109

81. Anz D, Thaler R, Stephan N, Waibler Z, Trauscheid MJ, Scholz $\mathrm{C}$, et al. Activation of melanoma differentiation-associated gene 5 causes rapid involution of the thymus. J Immunol. (2009) 182:6044-50. doi: 10.4049/jimmunol.0803809

82. Liu C, Li B, Cheng Y, Lin J, Hao J, Zhang S, et al. MiR-21 plays an important role in radiation induced carcinogenesis in BALB/c mice by directly targeting the tumor suppressor gene Big-h3. Int J Biol Sci. (2011) 7:347-63. doi: 10.7150/ijbs.7.347

83. Liu C, Gao F, Li B, Mitchel RE, Liu X, Lin J, et al. TLR4 knockout protects mice from radiation-induced thymic lymphoma by downregulation 
of IL6 and miR-21. Leukemia (2011) 25:1516-9. doi: 10.1038/leu. 2011.113

84. Li B, Sun M, Gao F, Liu W, Yang Y, Liu H, et al. Up-regulated expression of miR-23a/b targeted the pro-apoptotic Fas in radiation-induced thymic lymphoma. Cell Physiol Biochem. (2013) 32:1729-40. doi: 10.1159/0003 56607

85. Ilnytskyy Y, Zemp FJ, Koturbash I Kovalchuk, O. Altered microRNA expression patterns in irradiated hematopoietic tissues suggest a sex-specific protective mechanism. Biochem Biophys Res Commun. (2008) 377:41-5. doi: 10.1016/j.bbrc.2008.09.080

86. Gao F, Chen S, Sun M, Mitchel RE, Li B, Chu Z, et al. MiR-467a is upregulated in radiation-induced mouse thymic lymphomas and regulates apoptosis by targeting Fas and Bax. Int J Biol Sci. (2015) 11:109-21. doi: 10.7150/jibs.10276

87. Huang A, Zhang H, Chen S, Xia F, Yang Y, Dong F, et al. miR-34a expands myeloid-derived suppressor cells via apoptosis inhibition. Exp Cell Res. (2014) 326:259-66. doi: 10.1016/j.yexcr.2014.04.010

88. Osada M, Jardine L, Misir R, Andl T, Millar SE, Pezzano M. DKK1 mediated inhibition of Wnt signaling in postnatal mice leads to loss of TEC progenitors and thymic degeneration. PLoS ONE (2010) 5:e9062. doi: 10.1371/journal.pone.0009062

89. Akiyama T, Shimo Y, Yanai H, Qin J, Ohshima D, Maruyama Y, et al. The tumor necrosis factor family receptors RANK and CD40 cooperatively establish the thymic medullary microenvironment and self-tolerance. Immunity (2008) 29:423-37. doi: 10.1016/j.immuni.2008.06.015

90. Bleul CC, Boehm T. BMP signaling is required for normal thymus development. J Immunol. (2005) 175:5213-21. doi: 10.4049/jimmunol.175.8.5213

91. Hauri-Hohl MM, Zuklys S, Keller MP, Jeker LT, Barthlott T, Moon AM, et al. TGF-beta signaling in thymic epithelial cells regulates thymic involution and postirradiation reconstitution. Blood (2008) 112:626-34. doi: 10.1182/blood-2007-10-115618

92. Chen P, Zhang H, Sun X, Hu Y, Jiang W, Liu Z, et al. microRNA-449a modulates medullary thymic epithelial cell differentiation. Sci Rep. (2017) 7:15915. doi: 10.1038/s41598-017-16162-2

93. Bravo-Nuevo A, O'Donnell R, Rosendahl A, Chung JH, Benjamin LE, Odaka C. RhoB deficiency in thymic medullary epithelium leads to early thymic atrophy. Int Immunol. (2011) 23:593-600. doi: 10.1093/intimm/ dxr064

94. Hauri-Hohl M, Zuklys S, Holländer GA, Ziegler SF. A regulatory role for TGF-beta signaling in the establishment and function of the thymic medulla. Nat Immunol. (2014) 15:554-61. doi: 10.1038/ni.2869

95. Rossi SW, Kim MY, Leibbrandt A, Parnell SM, Jenkinson WE, Glanville SH, et al. RANK signals from CD4(+)3(-) inducer cells regulate development of Aire-expressing epithelial cells in the thymic medulla. J Exp Med. (2007) 204:1267-72. doi: 10.1084/jem20062497

96. Sun X, Liu S, Chen P, Fu D, Hou Y, Hu J, et al. miR-449a inhibits colorectal cancer progression by targeting SATB2. Oncotarget (2017) 8:100975-88. doi: $10.18632 /$ oncotarget. 10900

97. Nehls M, Pfeifer D, Schorpp M, Hedrich H, Boehm T. New member of the winged-helix protein family disrupted in mouse and rat nude mutations. Nature (1994) 372:103-7.

98. Nehls M, Kyewski B, Messerle M, Waldschutz R, Schüddekopf K, Smith AJ, et al. Two genetically separable steps in the differentiation of thymic epithelium. Science (1996) 272:886-9.

99. Cheng L, Guo J, Sun L Fu, J, Barnes PF, Metzger D, et al. Postnatal tissuespecific disruption of transcription factor FoxN1 triggers acute thymic atrophy. J Biol Chem. (2010) 285:5836-47. doi: 10.1074/jbc.M109.072124
100. Chen L, Xiao S, Manley NR. Foxn1 is required to maintain the postnatal thymic microenvironment in a dosage-sensitive manner. Blood (2009) 113:567-74. doi: 10.1182/blood-2008-05-156265

101. Candi E, Rufini A, Terrinoni A, Giamboi-Miraglia A, Lena AM, Mantovani R, et al. DeltaNp63 regulates thymic development through enhanced expression of FgfR2 and Jag2. Proc Natl Acad Sci USA. (2007) 104:11999-2004. doi: 10.1073/pnas17134 58104

102. Senoo M, Pinto F, Crum CP, McKeon F. p63 Is essential for the proliferative potential of stem cells in stratified epithelia. Cell (2007) 129:523-36. doi: 10.1016/j.cell.2007.02.045

103. Kushwaha R, Thodima V, Tomishima MJ, Bosl GJ, Chaganti RS. miR-18b and miR-518b Target FOXN1 during epithelial lineage differentiation in pluripotent cells. Stem Cell Dev. (2014) 23:1149-56. doi: 10.1089/scd.2013.0262

104. Yuan S, Li F, Meng Q, Zhao Y, Chen L, Zhang H, et al. Post-transcriptional regulation of keratinocyte progenitor cell expansion, differentiation and hair follicle regression by miR-22. PLoS Genet. (2015) 11:e1005253. doi: 10.1371/journal.pgen.1005253

105. Jackson SJ, Zhang Z, Feng D, Flagg M, O'Loughlin E, Wang D, et al. Rapid and widespread suppression of self-renewal by microRNA203 during epidermal differentiation. Development (2013) 140:188291.doi: $10.1242 /$ dev.089649

106. Lena AM, Shalom-Feuerstein R, Rivetti di Val Cervo P, Aberdam D, Knight RA, Melino G, et al. miR-203 represses 'stemness' by repressing DeltaNp63. Cell Death Differ. (2008) 15:1187-95. doi: 10.1038/cdd.2008.69

107. Ørom UA, Lim MK, Savage JE, Jin L, Saleh AD, Lisanti MP, et al MicroRNA203 regulates caveolin-1 in breast tissue during caloric restriction. Cell Cycle (2012) 11:1291-5. doi: 10.4161/cc.19704

108. Chikh A, Matin RN, Senatore V, Hufbauer M, Lavery D, Raimondi C, et al. iASPP/p63 autoregulatory feedback loop is required for the homeostasis of stratified epithelia. EMBO J. (2011) 30:4261-73. doi: 10.1038/emboj.2011.302

109. Antonini D, Russo MT, De Rosa L, Gorrese M, Del Vecchio L, Missero C. Transcriptional repression of miR-34 family contributes to p63-mediated cell cycle progression in epidermal cells. J Invest Dermatol. (2010) 130:1249-57. doi: 10.1038/jid.2009.438

110. Burnley P, Rahman M, Wang H, Zhang Z, Sun X, Zhuge Q, et al. Role of the p63-FoxN1 regulatory axis in thymic epithelial cell homeostasis during aging. Cell Death Dis. (2013) 4:e932. doi: 10.1038/cddis.2013.460

111. Matsuo T, Noguchi Y, Shindo M, Morita Y, Oda Y, Yoshida E, et al. Regulation of human autoimmune regulator (AIRE) gene translation by miR-220b. Gene (2013) 530:19-25. doi: 10.1016/j.gene.2013.08.105

112. Wang W, Wang L, Ruan L, Oh J, Dong X, Zhuge Q, et al. Extracellular vesicles extracted from young donor serum attenuate inflammaging via partially rejuvenating aged T-cell immunotolerance. FASEB J (2018). 32, 1-14. doi: 10.1096/fj.201800059R

Conflict of Interest Statement: The authors declare that the research was conducted in the absence of any commercial or financial relationships that could be construed as a potential conflict of interest.

Copyright $\odot 2018 \mathrm{Xu}$, Gan, Ning and Wang. This is an open-access article distributed under the terms of the Creative Commons Attribution License (CC BY). The use, distribution or reproduction in other forums is permitted, provided the original author(s) and the copyright owner(s) are credited and that the original publication in this journal is cited, in accordance with accepted academic practice. No use, distribution or reproduction is permitted which does not comply with these terms. 